\title{
Response 1
}

\section{Applied linguistics as transdisciplinary practice: What's in a prefix?}

\author{
H. G. Widdowson \\ University of Vienna
}

The contributors to this AILA Review resume a debate about the disciplinary status of applied linguistics that has been going on for at least half a century. Their aim, however, is not to provide a retrospective review of the issues raised in this debate, so they see no need to make any reference to it. Rather their aim is to supersede it by proposing an alternative conceptualisation of applied linguistics and one that is more attuned to the epistemological temper of the times. This makes for much thought-provoking reading in that it raises many a critical issue worth pondering on. But how far, one needs to ask, does this reconceptualization really lead to a more enlightened way of thinking about applied linguistics?

The purpose of applied linguistics is to engage with problems in the real world involving the use of language. This is its raison d'être, which distinguishes it from other areas of enquiry. But it is also said to have another distinctive feature which concerns not its purpose but the means for achieving it: that these means are necessarily interdisciplinary. This is how the editors of the journal Applied Linguistics put it several years ago:

It is perhaps uncontroversial to claim that applied linguistics, in becoming more interdisciplinary, is better prepared for the principled handling of a range of distinct types of real world issues, and more critically aware of its methodologies.

(Bygate and Kramsch, 2000, p. 2)

The assumption is that it is interdisciplinarity that primarily defines what applied linguistics is all about because it provides the necessary means for the handling of real-world issues, and that the more interdisciplinary it is, the more effective it becomes in handling them. This would seem to be consistent with what the editors of this issue of the AILA Review say in their introduction: 
Applied linguists draw on various disciplinary insights to illuminate their angle on the practical problem at hand, but ultimately their goal is not to construct any particular discipline, but to adopt a theme that will enable them to solve problems of the practice. Thus, one could say, paraphrasing Pierre Bourdieu, that Applied Linguistics is a "theory of the practice" [...].

Although it is conceded that the goal is to solve practical problems, the focus is still on the disciplinary means which might provide a general 'theory of practice' with reference to which particular problems will be resolved. So, though 15 years apart, both statements agree that applied linguists draw on various disciplinary insights to illuminate their angle on practical problems and so prepare them to handle real world issues. Where then is the new perspective?

It lies in a different view of how these disciplinary insights are drawn on. One is inter-and other is trans-. So, what is in a prefix? The term 'interdisciplinary' is said to imply that insights are carried over intact from separately defined disciplines so that applied linguistics might appear to be a kind of theoretical patchwork. But insights have to be meshed or woven together in a conceptual fusion so that their disciplinary distinctiveness is effaced. So essentially applied linguistics is not an interdisciplinary but a transdisciplinary kind of enquiry.

And as such, the argument goes, it can be represented as particularly well suited to the illumination and handling of language issues in the real world. For language use also transcends the borders that supposedly define different languages and cultures. People do not communicate by simply conforming to one set of linguistic rules or cultural conventions, or by inter-lingually code switching from one to another. It is not that they cross lingua-cultural borders, they efface them and create new relational alignments in the communicative process. They engage in translingual, trans-cultural languaging, and what they produce is necessarily transient, creative, emergent and of course complex. If this is what language is really like, then this is what applied linguistics should be able to handle. A transcendental linguistic phenomenon calls for a correspondingly transcendental disciplinarity.

From this point of view, it is certainly the case that mainstream linguistics in its various disciplinary versions does not provide much in the way of illuminative insights. On the contrary, linguists and sociolinguists, apparently unaffected by the new enlightenment, still for the most part persist in misrepresenting the real nature of language by dividing it up into distinct linguistic entities. They identify features that delimit different languages and language varieties and draw isoglossic lines to map out dialect boundaries, when in reality there are no such limits and boundaries. In short, they reduce language to an unreal abstraction remote from the way it is actually experienced by its users. In so doing they can be said to be in thrall to a misconceived view of language that dates back to de Saussure and his concept of langue. 
What needs to be borne in mind, however, is that de Saussure was concerned with identifying the methodological scope of what was amenable to study. His purpose was to define a discipline of linguistics, not the nature of langage - language as a whole. It was precisely because he recognised that the actual use of language as parole is fluid, variable, complex and so on that he eliminated it from disciplinary consideration.

And this abstraction from the actual is what all disciplines do. That is their raison d'être. Disciplines are designed to generalise from particulars, to find commonalities underlying apparent difference, and in so doing are bound to bring some things into conceptual focus and eliminate others. Disciplines define their own limits of enquiry, their own distinctive conceptual and methodological borders. Disciplines in this sense are kinds of academic restrictive practices. It is their very limitation that is the enabling condition for providing insights. No discipline represents experienced reality and it would have no value if it did. Of course, you can argue that the theoretical and methodological limits of a particular discipline are too restrictively drawn, too remote to provide insights of any significance. But limitation there must be. No limitation, no insights.

The question then arises as to how these limitations can be effaced, and the insights drawn from different disciplines be transcendentally meshed together as applied linguistics supposedly requires them to be? The answer appears to be that such transdisciplinarity involves transcending the very notion of discipline itself.

There are currently roughly two main conceptions of transdisciplinarity that are represented in this special issue and that seek to transcend two different views on the notion of academic discipline. The first is discipline as the sole principle for organizing and controlling academic knowledge; the second is academic discipline as the exclusive source of legitimate knowledge.

The crucial issue raised here is the nature of knowledge. Academic disciplines are defined and distinguished by specific theoretical concepts and methodological principles which constitute an authorized version of knowledge. And a discipline, as the term suggests, requires acceptance of that authority and there are penalties if you do not - you fail your exam, for example, or your journal article is rejected. Other kinds of knowledge that do not meet disciplinary criteria do not count. So academic knowledge is by definition that which is organized and controlled by disciplines. This can of course be frustrating for individuals whose intellectual interests range across conventionalized disciplinary borders and who feel that these borders prevent them from engaging with the issues central to applied linguistics, particularly those concerned with language education. It is this what the paper by Chantelle Warner is centrally concerned with.

Warner records the complaints of scholars of applied linguistics in the United States that disciplinary confinement not only inhibits intellectual initiative but by 
only giving recognition to work that conforms to established thinking, sets conditions for tenure and promotion. Thus, scholars of literature, for example, are frustrated in their attempts to introduce what they see as a crucial literary perspective in language study. Warner's paper is about this regrettable situation in the United States and attempts to remedy it, which might be said to be a parochial matter, of little interest to the readers of an international review. But the paper can be read as prompting a critical consideration of more general issues about disciplinarity and the possibility of transcending it.

The point I made earlier is that what disciplines do is to authorize modes of enquiry, set the criteria for what counts as knowledge, and so essentially define the norms of what Kuhn refers to as 'normal science.' But of course, these norms are not fixed but, like languages indeed, fluid, adaptable and emergent. They are abstract concepts that can always be variably actualized by individuals, and when some variations, for one reason or another, get stabilized they become normal. So, disciplines are always subject to variation and change. And they vary and change under the influence of other disciplines. Like languages, disciplines are in contact through the individuals that actualize them, and in so doing bring about linguistic and disciplinary convergences. So, it is that features of one discipline, or language, conveniently defined as a stable construct, get interpreted and incorporated into another.

The general point to be made is that we can only understand concepts by relating them to our familiar ways of thinking and knowing. What has been called inter- disciplinary can never be the carrying over of concepts intact from one way of thinking to another: it is always a matter of individual interpretative adaptation whereby the concepts are incorporated, familiarized to become a different way of thinking. And when these individual interpretations become accepted by a particular community, so they become authorized as normal. The problem with terms like inter-disciplinarity is the same as that with terms like multi- or pluri-lingualism: they imply that disciplines and languages are stable set of features which can be transferred from one to another. But the only agency of variation and change is the individual and individuals are bound to interpret them in reference to their own realities. In short there is always only transdisciplinarity as there is always only translingualism.

So, the state of affairs that Warner's informants find so frustrating is endemic in all academic enquiry and dissatisfaction with established norms is the driving force for change. And this is apparent in how the disciplinary study of language has developed over the years. Warner's particular concern is that American academia, with the exception of a few enlightened scholars, has failed to recognize the applied linguistic relevance of literary scholarship. This may be so currently in the US but such failure is not so apparent if one looks further afield. In Europe, for example, there have been decades of extensive work on stylistics which, in combining linguistic analysis with literary interpretation and exploring ways of 
incorporating its insights into pedagogic practice, would presumably qualify as a transdisciplinary activity. Furthermore, the development of critical discourse analysis as a separate area of enquiry had its origins, as its early proponents explicitly stated, in literary criticism and then morphed by the incorporation of insights from linguistic and social theory to establish its own disciplinary identity, marked by its own acronym, CDA.

So, variation and change, the continual re-alignment of ways of thinking, is with disciplines, as with languages, an inevitable natural emergent process. But this is not to say that it is not convenient to suppose that they are stable entities. It is indeed socially and institutionally necessary to assume that they are, for conventionalized norms of thinking and behavior represent the bearings we take on reality, and which provide the normal limits without which individual creativity cannot be recognized at all. Indeed, it is the very existence of these limits that inspires individuals to subvert them.

Disciplines, then, like languages, are social constructs, convenient fictions we cannot do without. They do not, and cannot, represent actual experience: they are essentially abstract norms of knowing established by academic authority, institutionally represented as stable, but subject to continual variation and change. Of course, this authorization can also be authoritarian, and when imposed by a particularly powerful figure, dictatorial. Just such a figure was Professor Benjamin Jowett, the Master of Balliol College Oxford in the mid- nineteenth century. This is how he was described in lines written by his students:

First come I, my name is Jowett,

There's no knowledge but I know it.

I am Master of this college.

What I don't know isn't knowledge.

Jowett may be an extreme case, but it is easy to think of other examples, in academia and elsewhere, of how the influence of a powerful and/or charismatic figure is a crucial factor in defining a discipline, or any other set of institutionalized conventions, that regulates individual thinking and behavior. In these cases, disciplines imply disciples who are enjoined to follow in the ideological steps of the Master. But there are of course, other powerful influences at work as well. How disciplines are defined can also be determined by what is considered to be supportive of political or economic exigencies. Or commercial interests: what is striking in recent years, for example, is the influence of publishers on the drawing and confirming of disciplinary demarcation lines. Whenever an apparently new line of enquiry is opened up, at least one handbook makes an appearance to authorize its disciplinary status.

A factor which always poses a problem in the transference of insights across disciplines is that their conventions of thought, their discourses in a Foucault sense, 
are expressed in a terminology that makes them difficult to access for outsiders. As indicated earlier, the transference always involves interpretation whereby ideas are appropriated, and incorporated into a familiar way of thinking, and it is not always easy to know whether the difficulty is because of the unfamiliarity of the concepts, or simply of the novel terms they are couched in. This applies to all interpretation and so to the process of disciplinary transference whatever language is involved. But, as the paper by Anthony Liddicoat argues, the process becomes particularly problematic when the disciplinary discourses are formulated in the terms of a different linguistic system, when transference involves translation. Here the issue of conceptual equivalence becomes more acute, for the terms themselves may be associated with deeply entrenched attitudes and ways of thinking.

This raises the interesting Whorfian question of how far ways of thinking are influenced, even reduced, by the terms conventionally used to describe them, where the term and the concept become indivisibly fused into one by association. A case in point, raised in Liddicoat's paper, is the insistence of French-speaking scholars on the use of the term didactique des langues to describe what their English-speaking counterparts would call 'applied linguistics'. The French term linguistique appliquée can be taken as suggesting a direct application of linguistics to language pedagogy, especially perhaps since the word to word translation, of the French term (as distinct from its usual translation equivalence) is indeed 'linguistics applied. French does not allow this distinction to be expressed in linguistic terms, so another term is needed to refer to how French scholars conceive of their activity - one more closely concerned with pedagogic practice. Hence didactique des langues. It was precisely to mark this conceptual distinction that the alternative English terms were proposed by the present writer in 1980. And it was proposed not to define linguistics applied as a 'sub-field' of applied linguistics but on the contrary to argue that applied linguistics should be conceived as just the kind of activity that Liddicoat, and Warner, now advocate as 'transdisciplinary'.

Whether 'transdisciplinary' is the appropriate term to refer to this activity is another matter. It is clear that didactique des langues in focusing on the problemsolving aim of applied linguistics rejects linguistics as the sole informing discipline, but didactics also involves bringing together insights from different areas of knowledge and enquiry. Does this make it transdisciplinary? This brings us to the second question posed in the quotation cited earlier: are academic disciplines the exclusive source of legitimate knowledge?

What disciplines do, as argued earlier, is to authorize certain kinds of knowledge and ways of knowing. But there are, of course, innumerable other kinds, some explicitly authorized by religious or political orthodoxy, others implicitly defined by the socio-cultural customs and practices of particular communities. All are ways of knowing, representations of versions of reality, not easily distinguishable 
from belief. Many if not most are incompatible with each other, and potentially and often actually in conflict. And it is just this multiplicity of kinds of knowledge, overtly expressed through language, that give rise to the problems in the real world that applied linguistics purports to be able to handle.

If this is so, then it would seem to make sense to focus attention on analysing the actual problems by recognising these different kinds of knowledge, how they come about and how their differences might be reconciled. And it is just such a problem-oriented approach that is taken in the contributions of Daniel Perrin and Marlies Whitehouse in this collection. The reason why, as it seems to me, such an approach is to be commended is partly no doubt because it is consistent with my own view of applied linguistics (in e.g. Widdowson, 2005, 2017). But more importantly because the analysis of a problem identifies features of shared concern and involves all those who have a stake in dealing with it. And we know that in reconciling differences of whatever kind, there is nothing more effective than a common cause.

But how is this approach transdisciplinary? It is trans-knowledges certainly but the knowledges are by no means all of a disciplinary kind. It can be argued that disciplinary insights may help in analysing the problem by reformulating participant views so as to establish conceptual commonalities, but then the disciplinary ideas are subservient and expedient and relate to the problem not to each other, so their transdisciplinarity as such effectively disappears - and indeed has to disappear as a condition on resolving the problem.

And so, we return to the question I posed at the beginning: how does the disciplinarity, inter- or trans-, of applied linguistics serve as the essential enabling means for engaging with real world problems? There is a good deal of intellectually stimulating discussion in this review about the disciplinarity of applied linguistics. It concludes with a rhetorically impressive display by Alastair Pennycook in presenting an elaborate argument which proposes that disciplinarity should be dispensed with altogether in favour of what he calls a 'posthumanist epistemic assemblage'. It is not made clear, however, just how this innovative way of thinking prepares for the handling of real-world issues better than inter- or trans-disciplinarity. Pennycook says that we need to think of applied linguistics

..less in disciplinary or transdisciplinary terms and more as temporary assemblages of thought and action that come together at particular moments when language-related concerns need to be addressed.

The dealing with 'temporary assemblages of thought and action' is surely what Perrin and Whitehouse are actually doing in their applied linguistic work. But they do so in the name of transdisciplinarity. So, they use the term to label a conceptualization which is not only radically different but contradictory to that proposed 
by Pennycook. The reason for this, I would suggest, is that the authors of each paper are interpreting the term in reference to their own perspective: Pennycook theoretically focusing on the disciplinarity of applied linguistics, Perrin and Whitehouse practically focusing on the activity of problem solving. And there is no correspondence between them.

But applied linguistics, on the accepted definition of the field referred to earlier, crucially depends on establishing such correspondences, on demonstrating how disciplinarity, inter- or trans-, can be turned to practical use, and is indeed a precondition for the effective handling of real-world problems. This essential implicational relationship is not, however, what the papers in this review are mainly concerned to demonstrate. This is not to say that they do not engage with problems: on the contrary they do so in impressive analytic and scholarly fashion. But the problems they engage with have mainly to do with the relationship between disciplines rather than that between disciplines and domains of practice in the real world. As discussed earlier, disciplines will always be subject to variation and change as ideas get re-aligned and new paradigmatic ways of thinking emerge in a continual process of transdisciplinary adaptation. But the question for applied linguistics is not how this transdisciplinarity leads to a reconceptualization of academic research but what implications it has for the more effective handling of real-world issues.

Debates about the nature of applied linguistics have always tended to give primary attention to its disciplinarity, and of course there are pressing institutional advantages for doing so which are difficult to resist. For it gives applied linguistics the presentable image of academic respectability, decked out in the terminology in current fashion. Defining applied linguistics in terms of its disciplinarity, whichever prefix is preferred, may enhance its theoretical status as an academic field of enquiry, but it can also have the effect of distracting attention from its problem solving accountability - and it is this, after all, which alone justifies its existence in the first place.

\section{References}

Bygate, M. \& Kramsch, C. (2000). 'Editorial'. Applied Linguistics 21(1), 2.

Kramsch, C. (2015). Applied Linguistics. A theory of the practice. Applied Linguistics, 36(4), 454-465. https://doi.org/10.1093/applin/amv039

Widdowson, H. G. (2005). Applied linguistics, interdisciplinarity, and disparate realities. In P. Bruthiaux, D. Atkinson, W. G. Eggington, W. Grabe \& V. Ramanathan (Eds), Directions in Applied Linguistics. Multilingual Matters. 12-25.

Widdowson, H. G. (2017/forthcoming). Disciplinarity and disparity in applied linguistics. Plenary address, BAAL Annual Conference. 